\title{
Cholinergic Synapses and the Organization of Contrast Detection in the Crayfish Optic Lobe
}

\author{
Cindy Pfeiffer and Raymon M. Glantz \\ Department of Biology, Rice University, Houston, Texas 77251
}

The actions of acetylcholine (ACh) were examined on 4 classes of multicolumnar interneurons whose dendrites lie in close proximity to the putative cholinergic transmedullary neurons described in the companion report. ACh-elicited responses in each cell type resemble visually elicited synaptic events and persist following synaptic blockade with $20 \mathrm{~mm} \mathrm{CoCl}$.

Tangential cells exhibit a hyperpolarizing response to $\mathrm{ACh}$ that resembles the visual response in reversal potential and dependence on extracellular chloride. The visual response is potentiated by the anticholinesterase, neostigmine $(0.1$ mM). Visual and carbachol-elicited responses are blocked by nicotinic ganglionic antagonists (e.g., $10^{-6} \mathrm{M}$ pempidine) that are 10-100 times more potent than D-tubocurarine. Medullary amacrine cells exhibit depolarizing responses to $\mathrm{ACh}$ $\left(10^{-6} \mathrm{M}\right)$ and light with similar reversal potentials. The visual response is potentiated by neostigmine. Dimming fibers respond to light and $\mathrm{ACh}$ with a hyperpolarization that inhibits the maintained discharge. The sustaining fiber response to ACh reflects both direct responses and indirectly elicited synaptic actions. The direct action is a hyperpolarization possibly related to the visual "off-response." It is associated with an increased conductance and a reversal potential negative to the dark potential. The off-response is abolished by curare and pempidine and potentiated by neostigmine.

ACh appears to orchestrate several aspects of the dualchannel contrast detection system of the optic lobe. The actions of ACh on tangential cells, amacrine cells, and dimming fibers are all consistent with the effects of a spatially localized increment in light intensity and a corresponding local release of $\mathrm{ACh}$ in the retinotopic columnar array.

Several neurotransmitters and neuropeptides have been localized in arthropod optic lobes, particularly during the last decade. These findings include evidence for cholinergic function in the optic lobes of diptera (Buchner et al., 1986; Gorczyca and Hall, 1987) and moths (Maxwell and Hildebrand, 1981). In the companion report (Wang-Bennett et al., 1989) we describe high levels of $\mathrm{ACh}$ in the medullary neuropiles of crayfish optic lobe. Immunocytochemical evidence indicates that the $\mathrm{ACh}$ is principally contained in transmedullary neurons of the second and third optic neuromeres.

Received June 15, 1988; revised Oct. 21, 1988; acceptcd Oct. 29, 1988.

This work was supported by Grant BNS-8711141 from the National Science Foundation.

Correspondence should be addressed to Raymon M. Glantz, Department of Biology, Rice University, P.O. Box 1892, Houston, TX 77251.

Copyright (C) 1989 Society for Neuroscience $0270-6474 / 89 / 061872-11 \$ 02.00 / 0$
In contrast to the impressive progress in the cytochemical localization of transmitters, little is known regarding the functional significance of the various transmitters in the optic lobe. A notable exception is a recent study by Hardie (1987) that argues that histamine is the neurotransmitter of the photoreceptors in locusts.

Over the last few years we have developed a preparation for the analysis of visually elicited synaptic events in the neurons of the first 2 optic ganglia (lamina ganglionaris and medulla externa) of the crayfish cyestalk (Kirk, 1982; Kirk et al., 1982, 1983; Waldrop and Glantz, 1985a, b; Wang-Bennett and Glantz, $1987 \mathrm{a}, \mathrm{b})$. In the medulla externa, these events consist of graded depolarizations in the local amacrine neurons and sustaining fibers (SF, principal output cells of the medulla externa) and graded hyperpolarizations in tangential neurons and dimming fibers (DF). Since the dendrites of each of the above cell types intersect or lie in close proximity to the neurites of the cholinergic transmedullary neurons, we tested each cell type for responsiveness to $\mathrm{ACh}$ and carbachol. Our results support the conclusion that $\mathrm{ACh}$ mediates a chloride-dependent graded hyperpolarization of tangential cells and the graded depolarization of medullary amacrine cells. In addition, our results are not inconsistent with a role for $\mathrm{ACh}$ in the visually elicited hyperpolarizing response of dimming fibers and the hyperpolarizing "off-response" of SFs.

\section{Materials and Methods}

Physiological preparation. Adults of 2 crayfish species, Procambarus clarkii and Pacifasticus leniusculus, were prepared as in Kirk et al. (1982). Animals were cooled for $2 \mathrm{hr}$ at $4^{\circ} \mathrm{C}$, and then the blood was exchanged for crayfish saline through a $1.0 \mathrm{~cm}$ opening in the carapace over the pericardial cavity. The eye was cemented to the adjacent cephalic carapace, and the animal was then mounted in a Plexiglas chamber filled with chilled saline. The dorsal cuticle and hypodermis of the eyestalk were removed to expose the optic lobe. The bath temperature was maintained at $13^{\circ} \mathrm{C}$, and the bath was grounded by a silver-silver chloride electrode.

Micropipettes contained $2.0 \mathrm{M}$ potassium acetate and yielded tip resistances of about $80 \mathrm{M} \Omega$. The location of the electrode in the medulla externa (ME) largely determines the cell types encountered. Tangential cells were penetrated in the distal layers of the ME or the proximal external chiasm (Fig. 1, inset). Amacrine cells were impaled near the center of the ME (Fig. 6A) and DF (Fig. 8A) and SF (Fig. 9A) were penetrated in the proximal medulla near the internal chiasm.

Visual stimuli were directed to the eye with a $6 \mathrm{~mm}$ fiber optic light guide held $5 \mathrm{~cm}$ from the eye in a micromanipulator. The light source was a focused projector lamp, and stimulus presentation was controlled with an electromagnetic shutter and neutral density filters.

On a number of occasions the identity of the cell type was verified by iontophoresis of Lucifer yellow (Stewart, 1978) into the cell. The optic lobe was fixed, dehydrated, cleared, and examined in whole mount with incident fluorescence. The previously established functional criteria for cell identification (Kirk et al., 1982; Waldrop and Glantz, 1985a, b; 
A
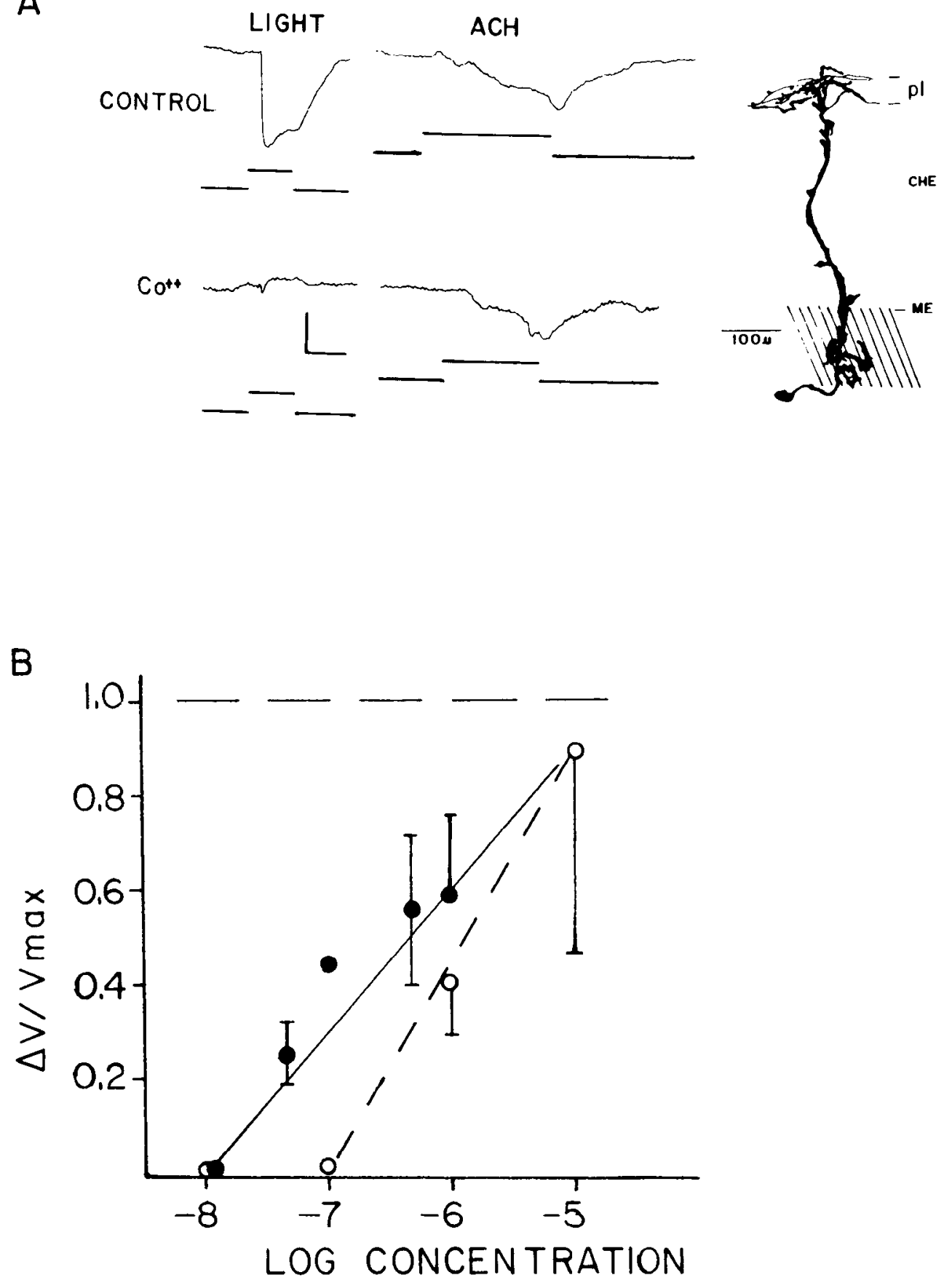

Figure 1. A, Tangential cell (Tan 1) responses to illumination and $1.0 \mu \mathrm{M} \mathrm{ACh}$ in control saline and saline containing $20 \mathrm{mM} \mathrm{CoCl}_{2}\left(\mathrm{Co}^{++}\right)$. Scale is $5 \mathrm{mV}$ and $1.0 \mathrm{sec}$. Inset at right is Tan 1 structure with dendrites in medulla externa $(M E)$, axon in external chiasm (CHE), and terminal arbor in lamina ganglionaris plexiform $(p l)$. Shading in ME indicates region occupied by cholinergic transmedullary neuron processes. $B$, Tan 1 dose-response to carbachol (filled circles) and ACh (open circles). Every response $(\Delta V)$ was normalized with respect to the reversal potential of the visual response $(V \max )$, and each data point but one is the mean of at least 4 determinations on separate preparations. The carbachol data point at $10^{-7} \mathrm{M}$ is the mean of 2 observations. Vertical bars indicate \pm SEM

\begin{abstract}
Wang-Bennctt and Glantz, 1987a, b) provided a correct assessment in every preparation so tested. These criteria are described in Results.

Pharmacology. All of the agents tested were applied via microinjection from micropipettes in the ME. The microinjections were carried out with pipettes having 1 of 2 tip sizes. The finer pipette tips $(<5 \mu \mathrm{m})$ delivered droplets with a maximum size of 50-60 $\mu \mathrm{m}$ diameter. The larger tips produced droplets of about $0.5 \mathrm{~mm}$. In the latter case, the droplet size assured that the entire ME was rapidly saturated with the test solution. The smaller droplets produced less desensitization and thus more consistent behavior in response to repeated tests with agonists. For a given concentration, some variation in agonist dosage can be achieved through control of the duration and the pressure of the pulse applied to the pipette. The pressure was varied from 10 to $60 \mathrm{psi}$ with a regulator. Pulse duration was controlled with a solenoid valve gated by a relay and pulse generator. In general, $\mathrm{ACh}$ and carbachol were applied with fine pipettes and other solutions were administered with the coarse pipettes.
\end{abstract}

In a few instances, the ACh and carbachol were applied iontophoretically from $20 \mathrm{M} \Omega$ double-barrelled electrodes. one barrel contained $1.0 \mathrm{M} \mathrm{ACh}$ and the second contained $1.0 \mathrm{M} \mathrm{NaCl}$. Injection currents were 5-100 nA for 10-100 msec. During these trials we observed $\mathrm{ACh}$ elicited responses, and on numerous occasions we observed synaptic activity associated with $\mathrm{NaCl}$ iontophoresis. The responses to $\mathrm{ACh}$ were larger and persisted beyond the end of the current pulse, while the responses to $\mathrm{NaCl}$ terminated at the end of the current pulse. Except in a few instances, however, we were unable to convince ourselves that the iontophoretic current was not contributing to the pharmacological result. Thus, we abandoned this procedure in favor of microinjection. We do, however, report the sensitivity to ACh iontophoresis as observed in the cleanest experiments. These data are provided only for purposes of comparison.

The pharmacological agents that we tested were ACh, carbachol, $d$-tubocurarine, pempidine, hexamethonium, mecamylamine atropine, and neostigmine (all from Sigma). Chemical synaptic transmission was 
Figure 2. Reversal potential of Tan 1 response to $1.0 \mu \mathrm{MACh} . A$, the 5 panels show ACh-elicited responses (top trace) during successively larger hyperpolarizing current pulses (second trace). Bar at bottom of each panel indicates timing of $\mathrm{ACh}$ injection. Scale (lower right) is $5 \mathrm{mV}, 5 \mathrm{nA}$, and $1.0 \mathrm{sec}$. $\mathrm{ACh}$ elicited response amplitude versus membrane potential $(\mathrm{Vm})$ for data of $A$. Membrane resting potential, -30 $\mathrm{mV} . C$, ACh-elicited (filled circles) and light-elicited (open circles) responses versus membrane potential $(\mathrm{Vm})$ from another preparation.
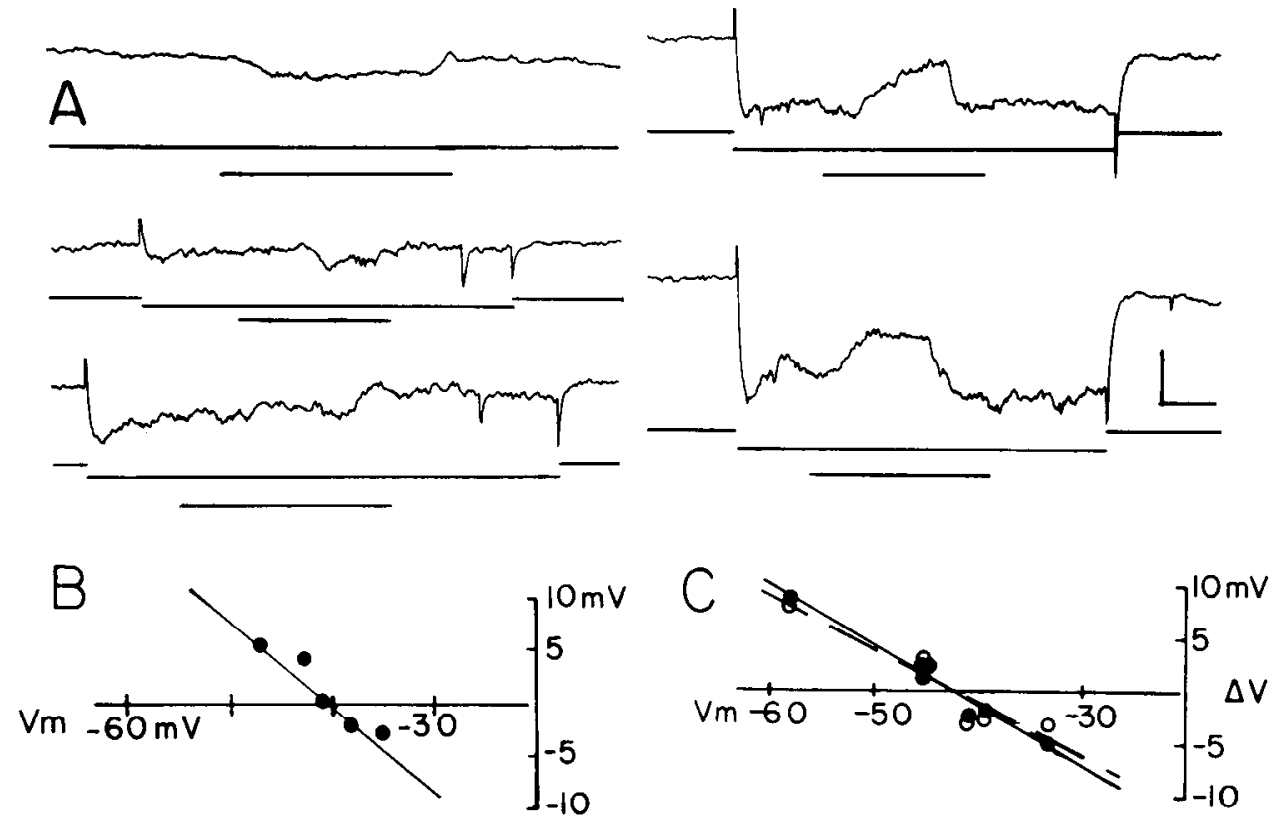

blocked by microinjection of $20 \mathrm{mM} \mathrm{CoCl}_{2}$. The $\mathrm{Co}^{2+}$ typically produced a complete block of visually elicited synaptic events in 2-3 min.

\section{Results}

The actions of $\mathrm{ACh}$ and carbachol were tested on 180 neurons impaled in the medulla externa. Of these, 163 could be unambiguously classified by functional criteria into 1 of 4 wellestablished cell groups. Each of the 4 groups was previously stained via iontophoresis with Lucifer yellow (Stewart, 1978) and/or HRP and is known to contain a dendritic arbor in the medulla externa. The remaining 17 neurons consisted of phasic "on" cells and putative transmedullary neurons. The phasic neurons exhibited no responsiveness to $\mathrm{ACh}$ and the transmedullary neurons only responded occasionally.

\section{Tangential cells}

Two classes of tangential cells can be distinguished morphologically and functionally (Wang-Bennett and Glantz, 1987b). One of these, Tan 1 (Fig. 1, inset), has a relatively narrow dendritic field in the medulla externa $(20-40 \mu \mathrm{m})$, an extensive (ca. 200 $\mu \mathrm{m}$ ) bistratified arbor in the lamina, a relatively thick axon (ca. $10 \mu \mathrm{m}$ ), and a soma in the medullary cell body area. The med- ullary arborization is coextensive with the neurites of the cholinergic transmedullary neurons (shaded area of Fig. 1, inset). The Tan 1 visual receptive fields are quite large (ca. $90^{\circ}$ ), and a light pulse elicits an intensity-dependent and sustained hyperpolarizing PSP (Fig. 1). Termination of an intense light pulse can produce a transient depolarization (Fig. $4 A$ ) that may, in turn, elicit one or several impulses.

$\mathrm{ACh}\left(>10^{-7} \mathrm{M}\right)$ and carbachol $\left(>10^{-8} \mathrm{M}\right)$ elicit dose-dependent hyperpolarizations in Tan 1 (Fig. 1) which are undiminished following synaptic blockade with $20 \mathrm{mM} \mathrm{Co}^{2+}$ (Fig. 1A). Halfmaximal responses are elicited by $1-2 \times 10^{-7} \mathrm{M}$ carbachol and about $2 \times 10^{-6} \mathrm{M} \mathrm{ACh}$ (Fig. $1 B$ ). The response is associated with an increase in input conductance and a reversal potential of $-40 \mathrm{mV}$, i.e., $10 \mathrm{mV}$ below the resting potential (Table 1; Fig. 2, $A, B$ ). These features compare favorably with those of the visual response (Fig. $2 C$ ).

An $85 \%$ reduction in the extracellular chloride concentration diminishes the visual PSP by 75\% and either abolishes or inverts the ACh-elicited response (Fig. 3A). Although reducing the extracellular $\mathrm{K}^{+}$concentration had predictable effects on the Tan 1 resting potential, it had only a small effect on the reversal potential of the visual response. An additional indication of the

Table 1. Comparison of visual and cholinergic responses in four classes of multicolumnar neurons

\begin{tabular}{|c|c|c|c|c|c|c|}
\hline & \multirow[b]{2}{*}{ Tangential cells } & \multirow[b]{2}{*}{ Amacrine cells } & \multicolumn{2}{|l|}{ Sustaining fibers } & \multicolumn{2}{|l|}{ Dimming fibers } \\
\hline & & & "On" & "Off" & "On" & "Off" \\
\hline Resting potential (mV) & $-28 \pm 1(64)$ & $-52 \pm 2(28)$ & $-59 \pm 1(65)$ & & $-41 \pm 4(9)$ & - \\
\hline Visual response $(\mathrm{mV})$ & $-11 \pm 1(64)$ & $+14 \pm 1(28)$ & $+16 \pm 1(65)$ & $-6 \pm 0.4(65)$ & $-14 \pm 3(9)$ & $+5 \pm 1(9)$ \\
\hline$V_{\mathrm{ACh}} / V_{\text {light }}{ }^{a}$ & $1.35 \pm 0.68(3)$ & $1.81 \pm 0.65(7)$ & $1.54 \pm 0.57(11)$ & $\sim 1.0(6)$ & $0.56 \pm 0.17(3)$ & - \\
\hline$E_{\mathrm{rcv}}($ light $)(\mathrm{mV})$ & $-44 \pm 2(12)$ & $-27 \pm 11(3)$ & $-19 \pm 9(7)$ & $-79 \pm 7(4)$ & $-61(1)$ & $-25(1)$ \\
\hline$E_{\mathrm{tev}}(\mathrm{ACh})(\mathrm{mV})$ & $-39 \pm 3(10)$ & $-23(2)$ & - & $-67+3(3)$ & $<-54(4)$ & - \\
\hline $\begin{array}{l}\text { [Carbachol] at } 0.5 V_{\max } \\
(\mathrm{nM})\end{array}$ & 100 & 50 & 10 & $10-100$ & 50 & - \\
\hline
\end{tabular}

All values are means \pm SE. Numbers in parentheses indicate sample size.

${ }^{a}$ For ACh concentration eliciting largest response. 


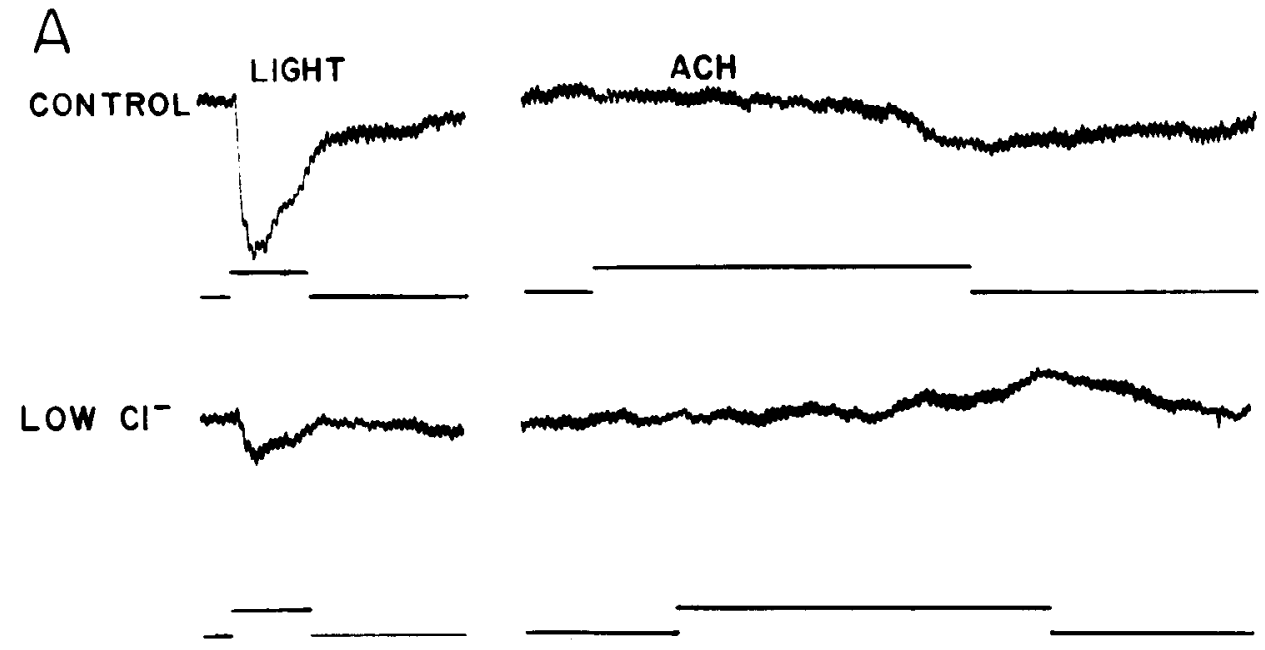

B

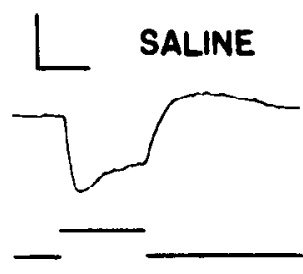

PICROTOXIN

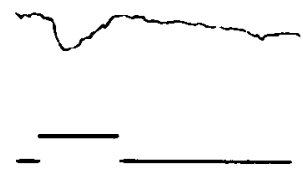

Figure 3. Chloride dependence of Tan 1 visual and ACh-elicited responses. $A$, Light- and ACh-elicited responses (upper traces) in control and low-chloride saline. Lower traces indicate light intensity in left-hand panels and $\mathrm{ACh}\left(5 \times 10^{-6} \mathrm{M}\right)$ injection in righthand panels. $B$, Tan 1 visual responses (upper traces) in control saline and in salinc containing $0.1 \mathrm{~mm}$ picrotoxin. Lower traces indicate light pulses. Scale, $5 \mathrm{mV}$ and $1.0 \mathrm{sec}$. involvement of a synaptic $\mathrm{Cl}^{-}$conductance is that $0.1 \mathrm{~mm}$ picrotoxin diminishes the initial transient of the Tan 1 visual response by $50-70 \%$ and abolishes the plateau phase (Fig. $3 B$ ).

The visually elicited hyperpolarizations are abolished or substantially diminished by nicotinic ganglionic antagonists mecamylamine, hexamethionium, and pempidine at $5 \times 10^{-5}-$ $10^{-6} \mathrm{M}$ but not at $10^{-7} \mathrm{M}$ (Fig. 4, $A-C$ ). D-Tubocurarine at $10^{-4}$ $\mathrm{M}$, however, produces only a $20-50 \%$ reduction in the visual response (Fig. $4 D$ ). Thus, pempidine and mecamylamine are at least 10-100 times more potent than curare in tangential cells. Qualitatively similar results (not shown) were also observed in agonist-elicited responses. The above pharmacological profile is consistent with the behavior of a nicotinic ganglionic receptor previously described (for arthropods) in crah stomatogastric ganglion (Marder and Paupardin-Tritsch, 1978). It is interesting to note that the depolarizing "off" response is generally unaffected by the nicotinic antagonists and even appears to be enhanced by pempidine (Fig. $4 C$ ).

The anticholinesterase, neostigmine, when applied in small doses (50 $\mu \mathrm{m}$ droplets), increases the visual response by $100 \%$ at $10^{-4} \mathrm{M}$ (Fig. 5). In general, neostigmine elevates the visual response voltage to saturation amplitude. The action of neostigmine on the visual response implies that the sensitivity to $\mathrm{ACh}$ is substantially underestimated by the data of Figure $1 B$, which was obtained without a cholinesterase block. Doses of neostigmine that exceed $0.1 \mu \mathrm{l}$ at $0.1 \mathrm{~mm}$ produce either no effect or a slight reduction in the light response.

Since Tan 1 has neurites in the lamina as well as the medulla (Figs. 1, 11), we tested the sensitivity of the Tan 1 lamina branches to ACh and carbachol. In 3 experiments the results were completely negative.

Tan 2 can be distinguished from Tan 1 by its broad medullary dendrite and a lamina process that is vertically oriented and spans the entire height of the lamina ganglion. Furthermore,
Tan2 has a distinctive visual response with 2 hyperpolarizing phases; a short latency, rapidly rising potential and a longer latency slower component. We examined the Tan 2 response to ACh and carbachol on 6 occasions (not shown). The limited results we obtained were similar to the Tan 1 findings, but the data set is both too small and incomplete to support any conclusions.

\section{Amacrine cells}

The amacrine cells are nonspiking, local interneurons of the medulla externa (Fig. 6A; Waldrop and Glantz, 1985b). They have a broad, bistratified dendritic arbor that occupies 2 transverse vertical planes in the medulla externa. Their receptive fields cover most of the monocular field of view (ca. $180^{\circ}$ ), and they respond to a light pulse with a graded depolarization (Fig. $6 B$ ). Following an initial transient, the depolarizing PSP decays to about $50 \%$ of its peak value. Upon depolarization with extrinsic current, amacrine cells inhibit the medullary elements that excite the SFs (Fig. 11).

Carbachol and $\mathrm{ACh}$ elicit graded depolarizations in amacrine cells (Fig. 6C). The ACh-elicited response-waveform occasionally ( 5 of 28 observations) resembles that of the visual response with a transient peak and a lower level plateau. The half-maximal response was obtained at $5 \times 10^{-8} \mathrm{M}$ carbachol. Both the $\mathrm{ACh}$ and visually elicited responses are associated with an increase in amacrine cell input conductance. The mean extrapolated reversal potential of the agonist-elicited response $(-23$ $\mathrm{mV}$ ) is similar to that of the light response, $-27 \mathrm{mV}$ (Fig. $6 \mathrm{D}$, Table 1). Neostigmine $(0.1 \mathrm{~mm})$ augments the amacrine cell visual response to saturation amplitude in a few minutes. We also probed amacrine cells with ACh iontophoresis. The sensitivity was about $2 \mathrm{mV} / \mathrm{nC}$. The agonist-elicited response persists after the light response is blocked by $20 \mathrm{~mm} \mathrm{Co}^{2+}$ (Fig. 7). 
A CONTROL

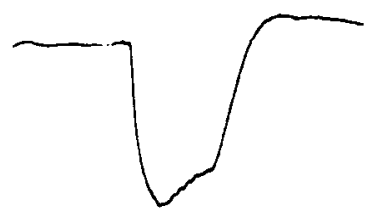

B
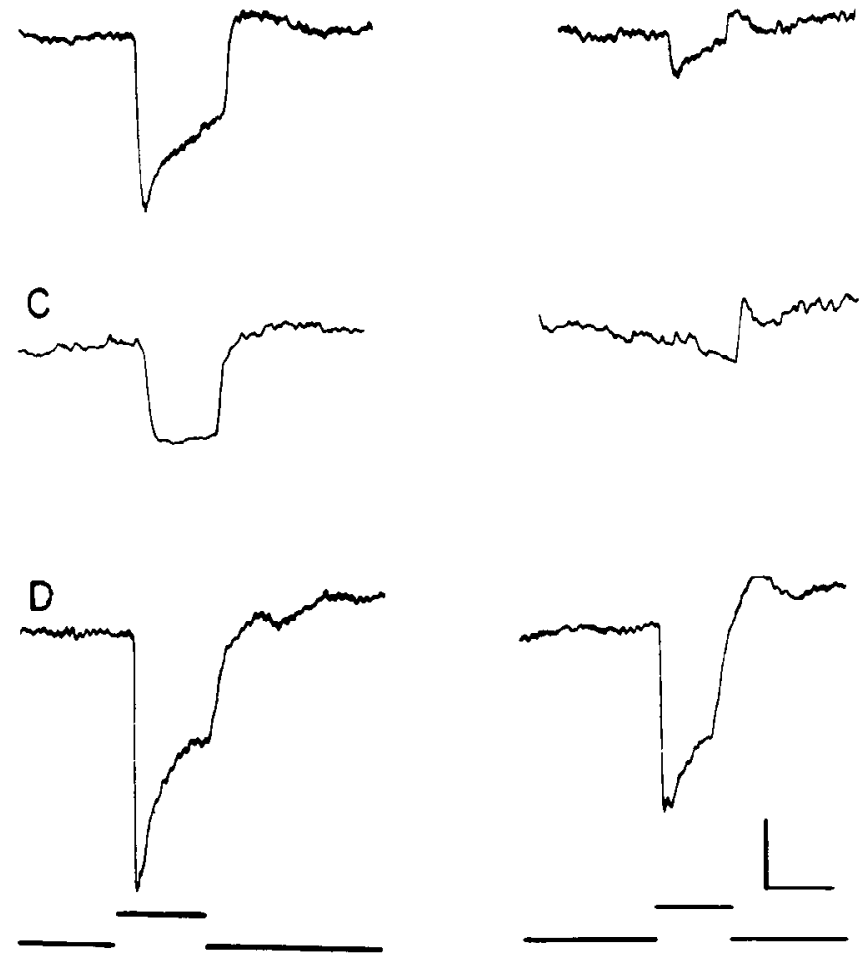

Figure 4. Action of nicotinic antagonists on Tan 1 visual responses. Left-hand panels are control visual responses; right-hand panels are visual responses in the presence of the antagonist. $A$, Mecamylamine, $10 \mu \mathrm{M} ; B$, hexamethonium, $50 \mu \mathrm{M} ; C$, pempidine, $1.0 \mu \mathrm{M} ; D$, D-tubocurarine, $0.1 \mathrm{~mm}$. Scale $5 \mathrm{mV}$ and $1.0 \mathrm{sec}$. Lower trace in $D$ is timing of light pulse.

\section{Dimming fibers}

The crayfish DFs were first described by Wiersma and Yamaguchi (1967) as tonic "off" neurons, on the basis of extracellular optic nerve recordings. Subsequent studies by Kirk (1982) re- vealed that the DF dendrites reside in the medulla externa (Fig. $8 A$ ), and their visual response is mediated by a compound IPSP that diminishes the "spontaneous" tonic discharge (Fig. $8 B$ ). The small caliber of the DFs has limited our sample size $(n=$ 9) and the tests performed.

$\mathrm{ACh}$ and carbachol elicit hyperpolarizing responses in DFs (Fig. $8 C$ ) and diminish or block the tonic discharge much as illumination does. The ACh-elicited response persists following $20 \mathrm{mM} \mathrm{Co}^{2+}$ (not shown), which blocks the visual response. A half-maximal response is obtained at $5 \times 10^{-8} \mathrm{M}$ carbachol.

\section{Sustaining fibers}

The SFs are the most prominent of the crayfish visual interneurons. Fourteen members of this class can be uniquely identified by their visual receptive fields (Wiersma and Yamaguchi, 1967) and the distribution of their planar dendrites in the medulla externa (Fig. 9A; Kirk et al., 1982). The SFs respond to illumination with a tonic discharge whose frequency is related to the amplitude of the graded, steady-state EPSP (Fig. 9C). The termination of an intense light pulse elicits a hyperpolarizing IPSP (Fig. 9C; Kirk et al., 1983). This "off-response" decays over several seconds and is associated with the attenuation or complete abolition of baseline synaptic activity.

$\mathrm{SF}$ behavior in response to $\mathrm{ACh}$ and carbachol is complicated by the fact that the SFs are the principal output cells of a medullary network comprised of at least 2 other ACh-sensitive neuronal types, i.e., tangential cells and medullary amacrine neurons. Tangential cell hyperpolarization indirectly excites SFs (Fig. 11; Wang-Bennett and Glantz, 1987b) and amacrine cell depolarization inhibits cells in the SF visual pathway (Waldrop and Glantz, 1985b). The visual responses of both cell types appear to be mediated by ACh.

Upon exposure to ACh $\left(10^{-6} \mathrm{M}\right)$ or carbachol $\left(10^{-8}-10^{-6} \mathrm{M}\right)$, the initial response of $64 \%$ of the SFs tested $(n=65)$ was a prolonged depolarization of $10-40 \mathrm{mV}$ in amplitude (Fig. 9B). The remaining cells exhibited either a diphasic (Fig. 9D) or hyperpolarizing response. In the depolarizing cells, repeated agonist stimulation frequently led to rapid desensitization of the depolarizing response and its replacement with a diphasic or hyperpolarizing response. In many cells, agonist-elicited responses were accompanied by an increase in the rate of discrete synaptic potentials. Such EPSPs elicited action potentials in the SF of Figure $9 D$.

$\mathrm{CoCl}_{2}$ (20 mM) diminished the visual EPSP by $90 \%$, substantially reduced the rate of synaptic bombardment and abolished

\section{SALINE}

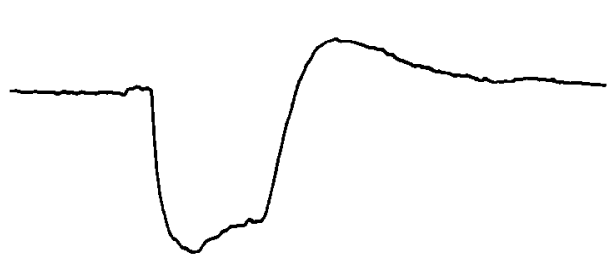

\section{NEOSTIGMINE}

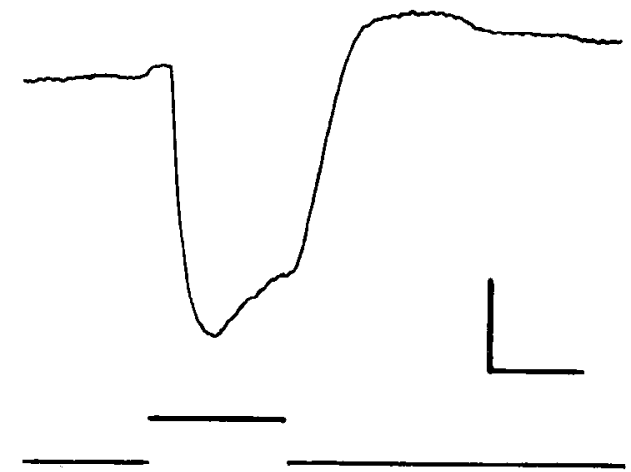

Figure 5. Effect of $0.1 \mathrm{~mm}$ neostigmine on the Tan 1 visual response. Top trace is Tan 1 membrane potential. Scale, $5 \mathrm{mV}$ and 1.0 sec. Bottom trace indicates timing of light pulse. 
A

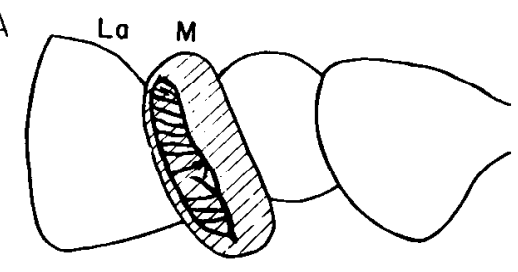

B

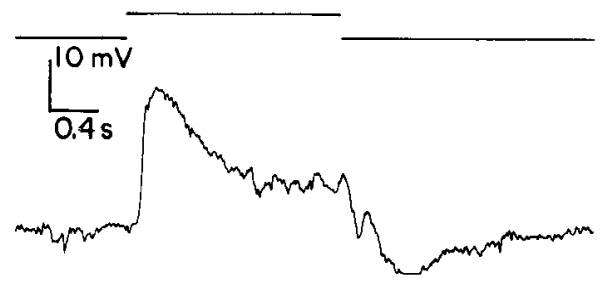

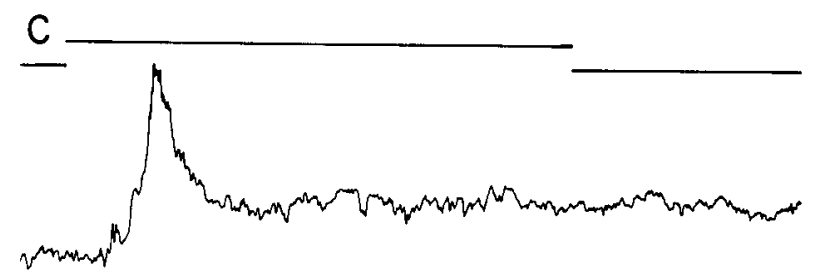

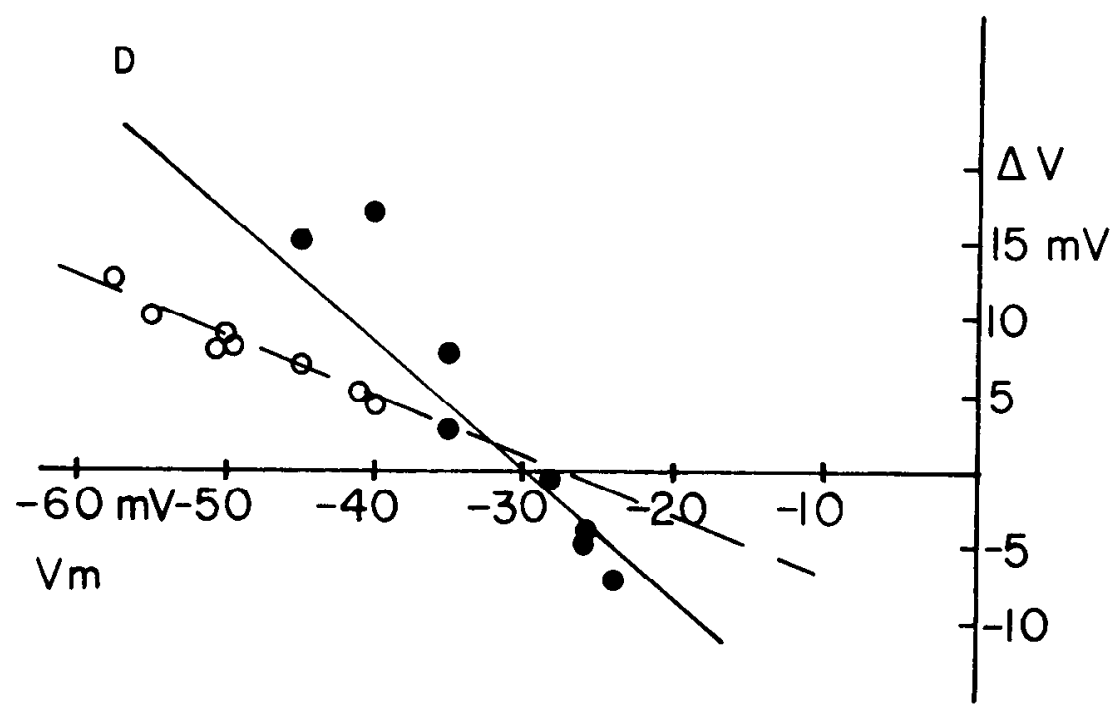

Figure 6. Amacrine cell visual and carbachol-elicited responses and reversal potentials. $A$, Sketch of the dorsal view of the amacrine cell bistratified neurite structure. Shaded area indicates region of transmedullary neuron neurites in the medulla externa $(M) . L a$ is the lamina. $B$, Amacrine cell visual response (lower trace). Top trace indicates timing of light pulse. $C$, Amacrine cell response to carbachol $\left(5 \times 10^{-8} \mathrm{M}\right.$; lower trace). Top trace indicates timing of carbachol pressure injection. $D$, Reversal potentials of amacrine cell visual responses (open circles) and carbacholelicited responses (closed circles). Carbachol concentration was $1.0 \mu \mathrm{M}$. Plot indicates response amplitude $(\Delta V)$ versus membrane potential $(\mathrm{Vm})$. Solid line is the least-square linear regression for carbachol responses with reversal potential at $-30 \mathrm{mV}$. Broken line is linear regression of visual responses with reversal potential of $-28 \mathrm{mV}$. Membrane resting potential was $-50 \mathrm{mV}$.

the depolarizing component of the carbachol-elicited response in 6 out of 7 tests (Fig. 9E). Following $\mathrm{Co}^{2+}$ application, the carbachol-elicited responses were hyperpolarizing. The separation of direct and indirect actions helps to clarify the puzzling result in Figure 9D, in which indirectly elicited EPSPs are superposed on the directly elicited hyperpolarization.

The average reversal potential of the stable agonist-elicited response was $-67 \mathrm{mV}$ (Fig. $9 F$, Table 1). This is $45 \mathrm{mV}$ negative to the reversal potential of the visually elicited EPSP (filled circles, Fig. $9 F$ ) and just a few millivolts below the SF resting potential. The reversal potential of the visual off-response, however, is about $12 \mathrm{mV}$ below that of the agonist-elicited response. The carbachol-elicited hyperpolarization was associated with a 2- to 4-fold increase in input conductance relative to resting input conductance.

In addition to synaptic blockade, $\mathrm{Co}^{2+}$ perfusion also led to a rapid depolarization of about $20 \mathrm{mV}$ in every SF tested. To compensate for the membrane potential shift in the above analysis, extrinsic hyperpolarizing current was injected into the SF to bring the membrane potential back to the resting level. An important implication of the $\mathrm{Co}^{2+}$-elicited depolarization is the possibility that SFs are under a hyperpolarizing synaptic bias in their "resting condition."

One interpretation of the above data is that ACh may mediate an inhibitory signal to the SFs that could be responsible for the hyperpolarizing off-response and/or the steady-state hyperpolarizing bias. Additional pharmacological studies indicate that ACh may contribute to both processes. Bath applied D-tubocurarine at $1 \mathrm{~mm}$ (Fig. 10B) depolarizes SFs by $5-10 \mathrm{mV}$ in a few seconds and suppresses the poststimulus hyperpolarization (compare Fig. 10B with the control in Fig. 10A). The identical effect is obtained with $\supset \mu \mathrm{M}$ pempidine injected into the neuropile. Neostigmine ( $0.1 \mathrm{~mm}$ ) has the opposite action (Fig. $10 \mathrm{D}$ ). It hyperpolarizes the SF by about $5 \mathrm{mV}$ and augments the hyperpolarizing "off" response. The effect of the hyperpolarization is particularly visible in SFs discharging in response to steady illumination (Fig. 10, E, F). In these cells the hyperpolarization is associated with a reduced firing rate and increased action 
Figure 7. Amacrine cell visually and carbachol-elicited responses in control saline and $20 \mathrm{~mm} \mathrm{CoCl}_{2}$. Upper traces indicate amacrine cell membrane potential in all panels. Lower traces indicate timing of light pulse in upper panels and timing of carbachol injection in lower panels.

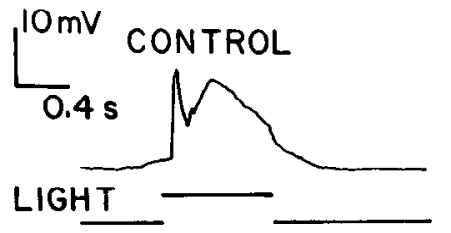

Cots

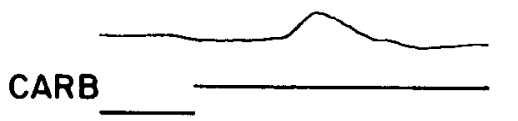

potential amplitude. The antagonists and the neostigmine do not have consistent effects on the amplitude of the visually elicited compound EPSP and associated discharge pattern. In most of the SFs tested, cholinergic antagonists reduced the footto-peak amplitude of the excitatory visual response but did not change the absolute peak response voltage (Fig. 10B). Neostigmine typically had the reverse action (Fig. 10F). Atropine (up
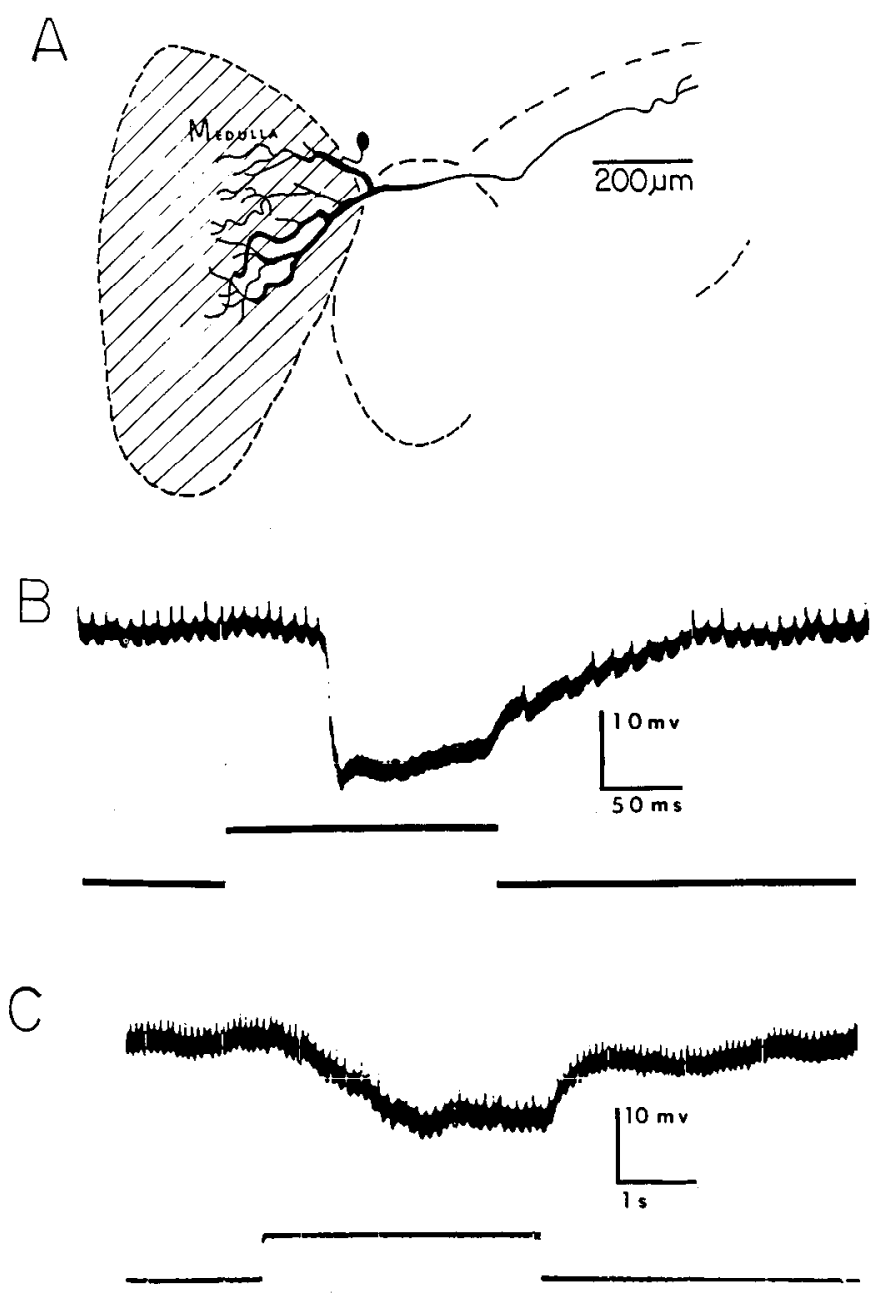

Figure 8. Dimming fiber responses to light $(B)$ and $10 \mu \mathrm{M}$ ACh $(C)$. $A$, Sketch of DF dendrites in the medulla externa (medulla). Shaded area corresponds to location of transmedullary neuron neurites in the medulla externa. $B$ and $C$, Visual and ACh-elicited responses, respectively (upper traces). Lower traces indicate timing of light pulse in $B$ and $\mathrm{ACh}$ injection in $C$. to $1.0 \mathrm{~mm}$ ) had no effect on any aspect of the SF visual response or resting potential.

\section{Discussion}

It is now well established that a neuron releasing one and the same neurotransmitter at each of its terminals can elicit a variety of actions in a population of follower cells. These phenomena are well documented in the Aplysia visceral ganglion (Blankenship et al., 1971; Wachtel and Kandel, 1971) and pleural ganglion (Kehoe, 1972a, b). Each postsynaptic response type is associated with a different set of ionic conductances and a distinguishable cholinergic pharmacological profile. In the lobster stomatogastric ganglion, the cholinergic pyloric dilator motoneurons elicit fast excitatory junction potentials (EJPs) in stomach muscles (Marder, 1976) and slow potassium-sensitive IPSPs in antagonist motoneurons (Marder and Eisen, 1984). The EJPs exhibit a ganglionic, nicotinic pharmacology (also found in crab: Marder and Paupardin-Tritsch, 1980), while the ganglionic IPSPs have a different pharmacological profile. A similar diversity exists among the receptors for the excitatory amino acid released by the photoreceptors in the fish and amphibian outer retinas (Miller and Slaughter, 1986).

Although the cholinergic transmedullary neurons constitute a cell class rather than a single neuron, it is not unreasonable to assume that each member of a class will have a similar synaptic action on each type of follower neuron as in the vertebrate outer retina. Thus, Tan 1 and DF are hyperpolarized by the onset of a light pulse, and the medullary amacrine is depolarized by the same stimulus regardless of the position of the stimulus in the visual field. Our assumption is that the several cholinergic transmedullary neurons constitute a homogeneous parallel ensemble which conveys similar signals at various positions in the columnar array. In accordance with this hypothesis, the AChelicited hyperpolarizing response in Tan 1 and DFs, and the depolarizing response in medullary amacrines may be construed to reflect the synchronous actions of the same class of presynaptic neuron. This hypothesis is consistent with the fact that the related physiological responses are coactivated by an increment in the level of illumination and exhibit similar response latencies following light onset. The SF off-response does not conform to this pattern. It is possible, however, that the offresponse is the terminal phase of an inhibitory process that is concurrent with excitation. Some indirect evidence for such a process is documented (Wiersma and Yamaguchi, 1967; Glantz, 1973).

The above argument presupposes that the cholinergic transmedullary neurons are directly presynaptic to the 4 classes of multicolumnar interneurons. There is no electron microscopic 
$A$

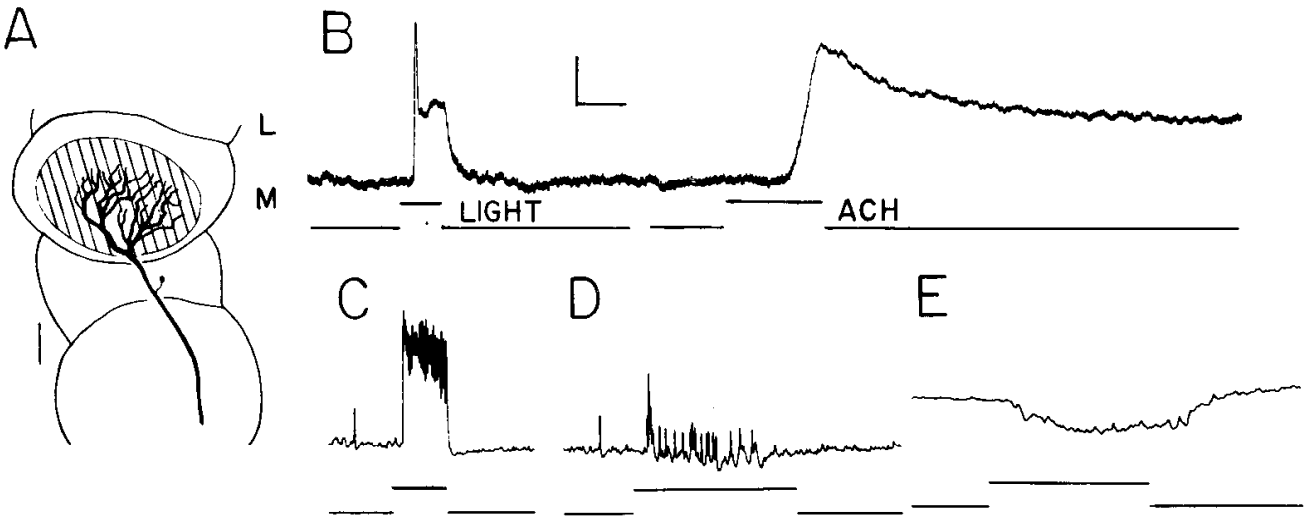

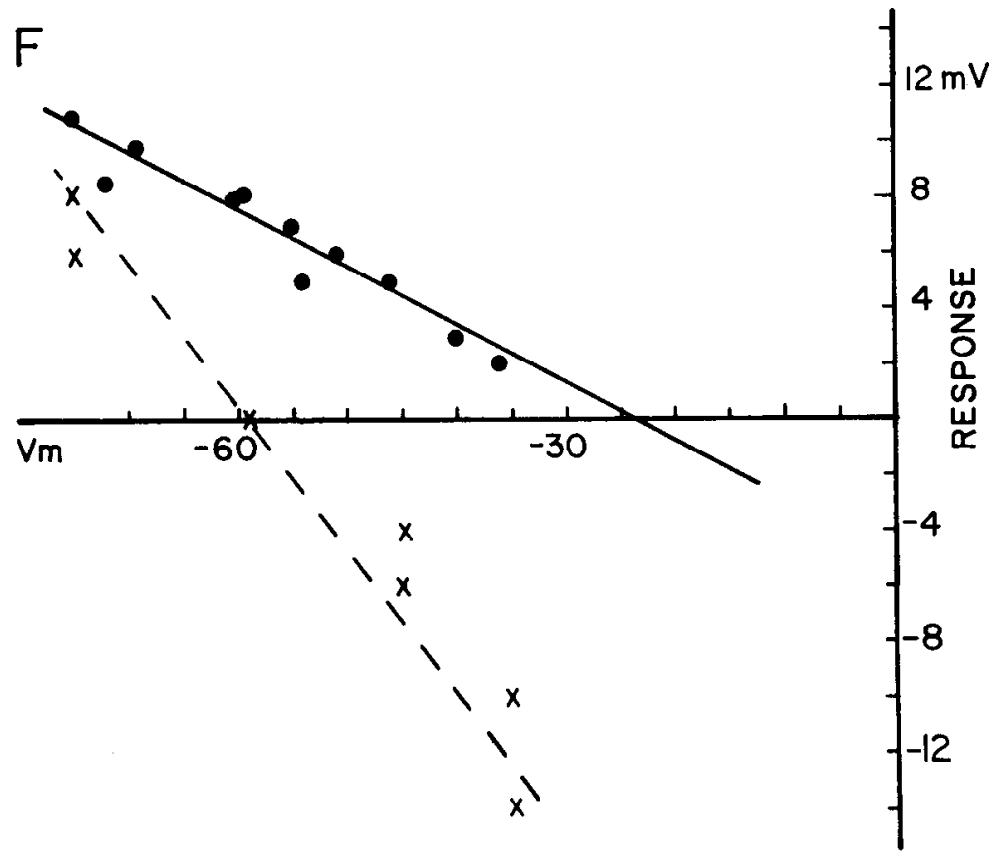

Figure 9. Sustaining fiber visual and ACh-elicited responses and reversal potentials. $A$, Diagram of SF dendritic arbor in the medulla externa $(M)$ Shaded area indicates region of cholinergic transmedullary neuron neurites. Scale (lower left) is $100 \mu \mathrm{M}$. $B$, SF responses (upper trace) to light and $10^{-6}$ $\mathrm{M}$ ACh pulses (lower traces). $C-E$, Visual $(C)$ and $\mathrm{ACh}(D)$ responses from another preparation. In $D, 10^{-6} \mathrm{M} \mathrm{ACh}$ elicits a mixture of depolarizing EPSPs and a slower hyperpolarizing potential. $E$ shows the ACh-elicited response in the presence of $20 \mathrm{~mm} \mathrm{CoCl}$. Scale is $5 \mathrm{mV}$ and $1.0 \mathrm{sec}$ throughout, $F, \mathrm{SF}$ response amplitude (Response) versus mcmbranc potential $(\mathrm{Vm})$ for responses elicited by light (filled circles) and $5 \times 10^{-7} \mathrm{M}$ carbachol $(\times)$. The cell had a membrane resting potential of $-60 \mathrm{mV}$. evidence to support this contention. The observed proximity of all the relevant processes is necessary but not sufficient to establish connectivity. The argument for the proposed synapses rests upon 3 types of findings: (1) there is a high concentration of ACh in the medulla; (2) the cholinergic transmedullary neurons are the only source of $\mathrm{ACh}$ observed (immunocytochemically) in the medulla externa; and (3) the pharmacology of the visual responses in 3 of the 4 cell types is consistent with a principal role for $\mathrm{ACh}$. The evidence for an exclusive source of ACh could be nullified by a more sensitive cytochemical assay for ACh. The argument for the role of ACh in the Tan1 visual response rests upon (1) the persistance of the ACh-elicited response following $\mathrm{Co}^{2+}$ perfusion, which blocks visual synaptic activity; (2) reduction or block of the visual response by the nicotinic ganglionic antagonists pempidine, mecamylamine, and hexamethonium; (3) augmentation of the visual response by the anticholinesterase neostigmine; and (4) the similarity in reversal potential and sensitivity to the extracellular chloride concentration of the ACh and visually elicited events; and (5) the measured $\mathrm{ACh}$ sensitivity relative to that reported in other arthropod neurons. Both Tan 1 and amacrine cells exhibit halfmaximal responses to $\mathrm{ACh}$ at about $2 \times 10^{-6} \mathrm{M}$ in the absence of a cholinesterase blocker. This sensitivity equals or exceeds that of a number of crustacean (Marder, 1974; Konishi and Kravitz, 1978; Marder and Paupardin-Tritsch, 1980; Yoshino et al., 1984) and insect (David and Sattelle, 1984; Callec, 1985; Suter and Usherwood, 1985) postsynaptic sites. A similar conclusion is supported by a comparison of carbachol sensitivities in the same preparations.

The Tan 1 visual response appears to be mediated by a nicotinic cholinergic receptor coupled to a chloride conductance. Although a similar profile is described for molluscan synapses (Blankenship et al., 1971; Kehoe, 1972b), it is unusual in arthropods. ACh-mediated IPSPs have been observed in lobster stomatogastric ganglion (Marder and Eisen, 1984), but they are mediated by a muscarinic-like receptor coupled to a potassium conductance. Conversely, inhibitory synapses associated with a chloride conductance are well known in arthropod nerve tissue, 
Figure 10. Effect of D-tubocurarine $(B)$ and neostigmine $(D$ and $F)$ on SF visual responses. $A$, control visual response with large hyperpolarizing "off-response." $B, \mathrm{D}$-Tubocurarine ( $1 \mathrm{~mm}$ ) depolarizes SF (indicated by baseline shift relative to $A$ ) and blocks the off-response. $C$, Control visual response in a second cell. $D$, Neostigmine $(0.1 \mathrm{~mm})$ hyperpolarizes cell and augments the off-response (compare to $C$ ). $E$, Control $\mathrm{SF}$ visual response in a third preparation. $F$, Neostigmine $(0.1 \mathrm{~mm})$ hyperpolarizes $\mathrm{SF}$ and augments foot to peak amplitude of action potentials. Upper trace is SF membrane potential in all panels. Scale is $5 \mathrm{mV}$ and $100 \mathrm{~ms}$. Lower trace indicates timing of light pulse.
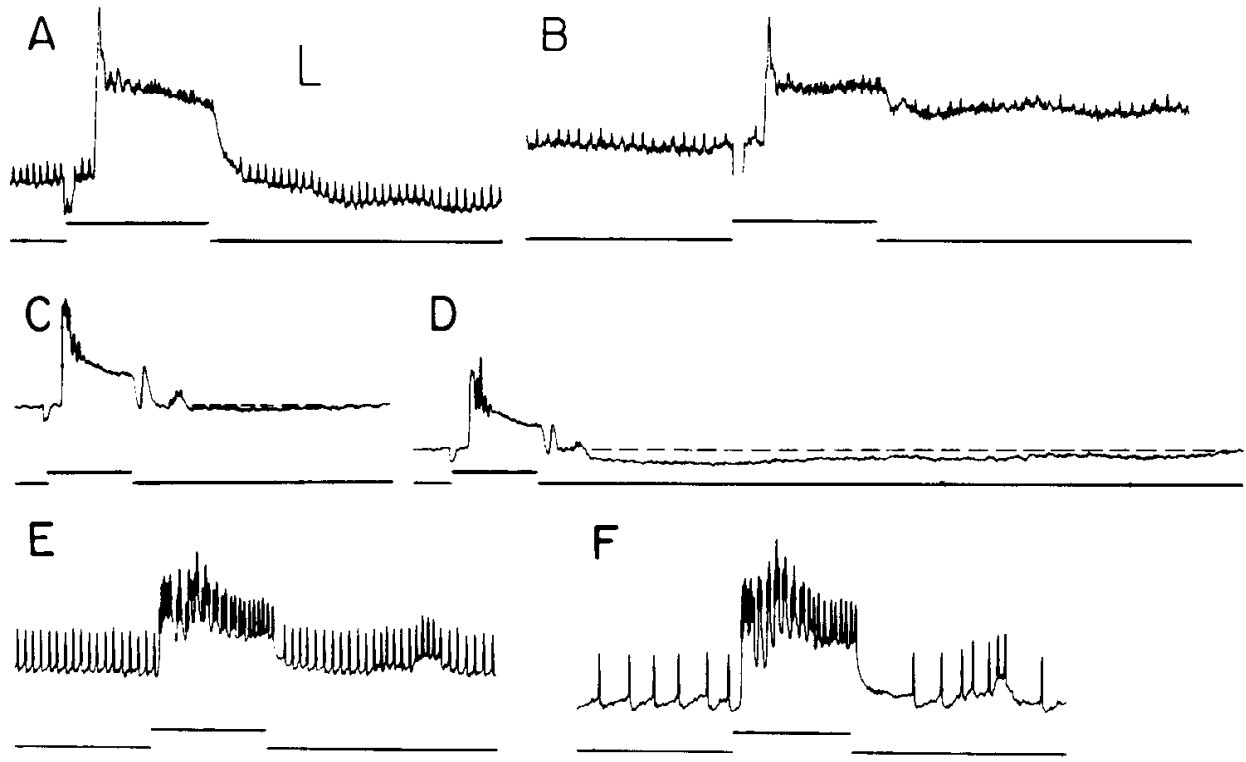

but they are generally mediated by GABA (Takeuchi and Takeuchi, 1966; Atwood, 1980; Callec, 1985) or glutamate (Marder and Paupardin-Tritsch, 1978; Marder and Eisen, 1984; Franke et al., 1986).

The interpretation of the SF data is complicated by the fact that the pharmacological analysis is confounded by either a large depolarization induced by $\mathrm{Co}^{2+}$ or agonist-elicited synaptic actions. Considering these caveats we tentatively interpret the SF results to indicate that $\mathrm{ACh}$ may mediate a hyperpolarizing dark potential and "off-response" in SFs. The dark potential is presumably mediated by continuous release of $\mathrm{ACh}$, and there is a good precedent for sustained transmitter release by resting neurons in the lobster stomatogastric ganglion (Graubard et al., 1983).

Since the visually elicited off-response is blocked by curare and pempidine and potentiated by neostigmine, it is likely to be cholinergic, which is consistent with the hyperpolarizing action of $\mathrm{ACh}$ and carbachol in $\mathrm{Co}^{2+}$-treated preparations. The reversal potential of the off-response, $-79 \mathrm{mV}$, is somewhat negative to that for carbachol, $-67 \mathrm{mV}$, which may indicate the participation of different ionic conductances and other transmitters.

Our results have several implications for the organization of the visual pathway in crayfish. Strausfeld and Nassel (1980), distinguish 6 classes of transmedullary neurons on the basis of their dendritic structures. An inference from our results is that the tangential cells, DFs, and amacrine cells may share a class of cholinergic inputs having only inhibitory actions on the SFs (Fig. 11). The notion that a different class of cell mediates columnar excitation of the SFs is consistent with an important
Figure 11. Diagrammatic summary of results and interpretation of medullary neuron synaptic interactions. Ovals indicate presynaptic terminals; open ovals have hyperpolarizing and closed ovals have depolarizing actions on postsynaptic elements. $R 1-R 7$ short axon photoreceptors which terminate on monopolar neurons $(M 1-M 4)$ in lamina plexiform layers. $T M$ indicates transmedullary monopolar neurons. Cholinergic TMs elicit hyperpolarizing PSPs in Tan1, Tan2, DFs, and SFs and depolarizing PSPs in medullary amacrine cells. One or more classes of noncholinergic TMs elicit depolarizing PSPs in SFs and DFs. Broken lines indicate possible polysynaptic pathways.

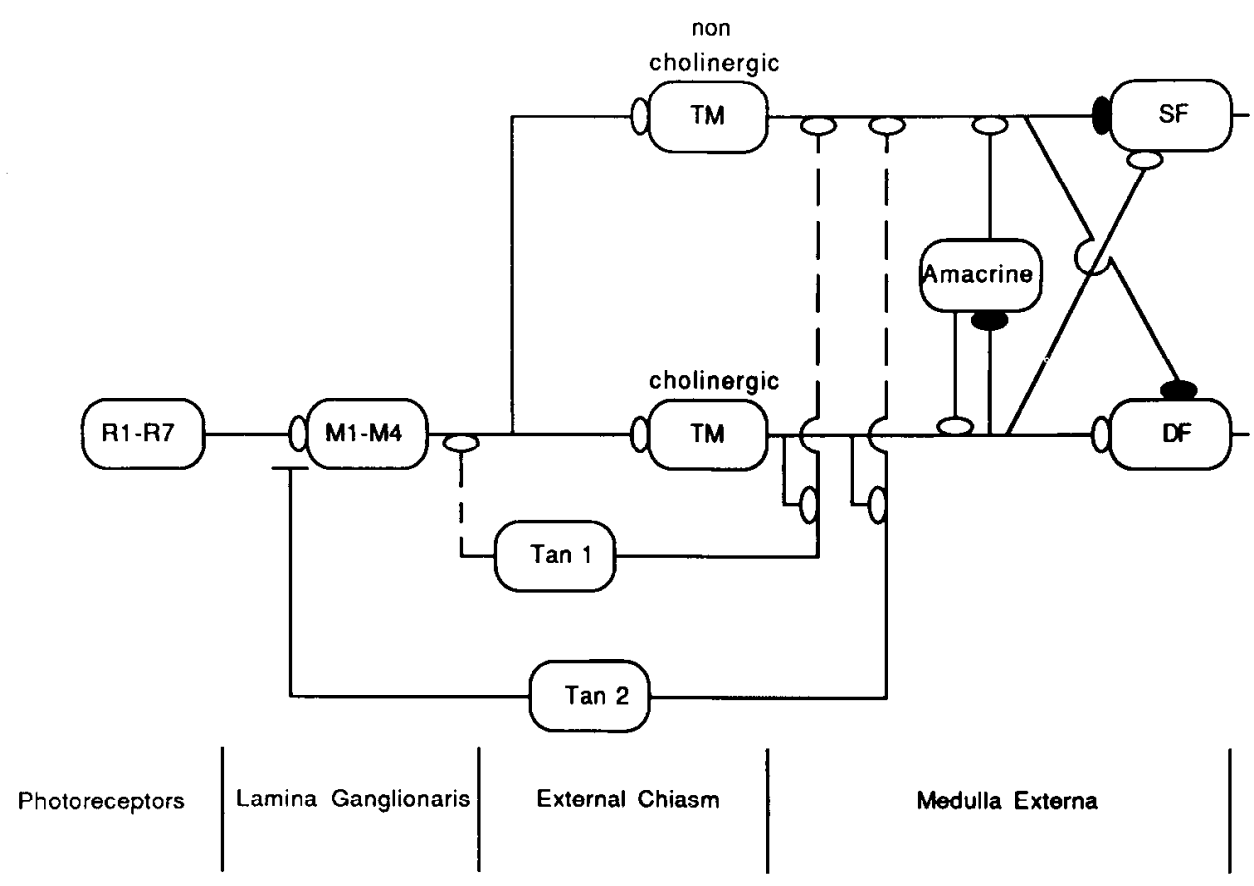


functional distinction in the medulla. The SF excitatory response is subject to powerful surround inhibition (Wiersma and Yamaguchi, 1967; Arechiga and Yanagisawa, 1973; Glantz, 1973). In previous studies (Waldrop and Glantz, 1985b), we have shown that this inhibition is mediated by amacrine cell action on medullary elements presynaptic to the SFs (Fig. 11). Neither the tangential nor the amacrine cell light response is subject to surround inhibition (Waldrop and Glantz, 1985b; Wang-Bennett and Glantz, 1987b). Although the evidence is rather indircet, it does suggest separate columnar pathways for the SF excitatory response on the one hand (Fig. 11, noncholinergic TM) and the visual signals to the amacrine and tangential cells (Fig. 11). This inference is in accord with the pharmacology of these responses.

In diptera, the homologs of the tangential cells appear, on the basis of their ultrastructure, to convey signals from the medulla to the lamina (Strausfeld and Campos-Ortega, 1977; Shaw, 1984). In crayfish, the relatively long latency of the Tan 1 visual response and the sensitivity to ACh injected in the medulla (but not the lamina) are also consistent with centrifugal function.

The SFs and DFs together constitute a dual-channel mechanism for detecting contrast and representing the distribution of light intensity in visual space (Yamaguchi and Ohtsuka, 1973). An increment in the level of illumination at any corneal location will excite a subset of SFs and inhibit a subset of DFs with overlapping receptive fields. This functional duality appears to have a neurochemical counterpart in the actions of ACh. Our preliminary studies indicate that the transmedullary neurons exhibit depolarizations graded with the light intensity in their receptive fields. Thus, we assume that the amount of $\mathrm{ACh}$ released at each locus in the retinotopic columnar array is proportional to the light intensity at a corresponding visual angle. The following $\mathrm{ACh}$ actions are consistent with the known functional connectivity and the dual contrast encoding mechanism. (1) ACh hyperpolarizes tangential cells: Extrinsic hyperpolarization of tangential cells indirectly excites SFs (Fig. 11) as does local illumination (Wang-Bennett and Glantz, 1987b); (2) ACh hyperpolarizes DFs and inhibits the dark discharge as does local illumination. (3) $\mathrm{ACh}$ and local illumination depolarize medullary amacrine cells. Extrinsic depolarization of amacrine cells inhibits the excitatory pathway to all SFs and indirectly excites DFs (Waldrop and Glantz, 1985b). Because the local excitatory effects of light exceed the inhibitory effects of the amacrine cell action, the net result is local excitation and surround inhibition in the SF array. This is the global action of local illumination. Thus, ACh, through its action on amacrine cells drives the surround inhibitory mechanism.

The ACh-elicited hyperpolarization of SFs may depart from the above scheme. If the cholinergic inhibitory action is concurrent with excitation, then it would tend to oppose contrast enhancement. Conversely, if the SF "off-response" is actually initiated on the termination of a light pulse, then it would reinforce the contrast mechanism in the temporal domain. The initiation of a synaptic action subsequent to light decrement would, however, require an independent presynaptic mechanism to provide for the phase shift. Previous studies (Waldrop, 1984) support the latter hypothesis. The hyperpolarizing offresponse is associated with a large and distinct increase in SF input conductance.

The above analysis does not address the direct excitation of SFs and DFs nor the "off-responses" of tangential cells. We assume these functions are the province of the noncholinergic columnar neurons and the many other transmitters known to be present in the medulla externa (Elofsson et al., 1982; Beltz and Kravitz, 1983; Elofsson, 1983; Siwicki and Bishop, 1986).

Our results imply that a single neurotransmitter, $\mathrm{ACh}$, plays multiple but coherent roles in the functional organization of the neuronal network subserving contrast detection. Neurochemical and pharmacological studies in the lobster postural control system (Harris-Warrick and Kravitz, 1984; Harris-Warrick, 1985) and the lobster stomatogastric ganglion (Flamm and HarrisWarrick, 1986; Marder et al., 1987) suggest a similar capacity for multiple concerted actions for serotonin, octopamine, and dopamine.

\section{References}

Arechiga, H., and K. Yanagisawa (1973) Inhibition of visual units in the crayfish. Vision Res. 13: 731-744.

Atwood, H. L. (1980) Synapses and neurotransmitters. In Biology of Crustacea, Vol. 3, H. L. Atwood and D. C. Sandeman, eds., pp. 105150, Academic, New York.

Beltz, B. S., and E. A. Kravitz (1983) Mapping of serotonin-like immunoreactivity in the lobster nervous system. J. Neurosci. 3: 583602.

Blankenship, J. E., H. Wachtel, and E. R. Kandel (1971) Ionic mechanisms of excitatory, inhibitory and dual synaptic actions mediated by an identified interneuron in abdominal ganglion of Aplysia. $\mathrm{J}$ Neurophysiol. 34: 76-91.

Buchner, E., S. Buchner, G. Crawford, W. T. Mason, P. M. Salvaterna, and D. B. Sattelle (1986) Choline acetyltransferase-like immunoreactivity in the brain of Drosophila melanogaster. Cell Tissue Res. 246: $57-62$.

Callec, J. J. (1985) Synaptic transmission in the central nervous system. In Comprehensive Insect Physiology Biochemistry and Pharmacology, Vol. 5. G. Kerkut and L. I. Gilbert, eds., pp. 139-179, Pergamon, New York.

David, J. A., and D. B. Sattelle (1984) Actions of cholinergic pharmacological agents on the cell body membrane of the fast coxal depressor motoneurone of the cockroach (Periplaneta americana). $\mathbf{J}$. Exp. Biol. 108: 119-136.

Elofsson, R. (1983) 5-HT immunoreactivity in the central nervous system of the crayfish. Cell Tissue Res. 232: 221-236.

Elofsson, R., L. Laxmyr, E. Rosenglen, and C. Hansson (1982) Identification and quantitative measurements of biogenic amines and dopa in the central nervous system and haemolymph of the crayfish, $\mathrm{Pa}$ cifastacus leniusculus. Comp. Biochem. Physiol. 71c: 195-201.

Flamm, R. E., and R. M. Harris-Warrick (1986) Aminergic modulation of lobster stomatogastric ganglion. II. Target neurons of dopamine, octopamine and serotonin within the pyloric circuit. J. Neurophysiol. 55: 866-881.

Franke, Ch., H. Hatt, and J. Dudel (1986) The inhibitory chloride channel activated by glutamate as well as $\gamma$-amino-butyric acid (GABA). J. Comp. Physiol. 159: 591-609.

Glantz, R. M. (1973) Spatial integration in the crustacean visual system: Peripheral and central sources of nonlinear summation. Vision Res. 13: 1801-1814.

Gorczya, M. H., and J. C. Hall (1987) Immunohistochemical localization of choline acetyltransferase during development and in Cha mutants of Drosophila melanogaster. J. Neurosci. 7: 1361-1369.

Graubard, K., J. A. Raper, and D. K. Hartline (1983) Graded synaptic transmission between identified spiking neurons. J. Neurophysiol. 50: 508-521.

Hardie, R. C. (1987) Is histamine and neurotransmitter in insect photoreceptor? J. Comp. Physiol. 161: 201-213.

Harris-Warrick, R. M. (1985) Amine modulation of extension command element-evoked motor activity in the lobster abdomen. J. Comp. Physiol. 156: 875-884.

Harris-Warrick, R. M., and E. Kravitz (1984) Cellular mechanisms for modulation of posture by octopamine and serotonin in the lobster. J. Neurosci. 4: 1976-1993.

Kehoe, J. (1972a) Ionic mechanism of a two-component cholinergic inhibition in Aplysia neurons. J. Physiol. (Lond.) 225: 85-114.

Kehoe, J. (1972b) Three acetylcholine receptors in Aplysia neurones. J. Physiol. (Lond.) 225: 115-146. 
Kirk, M. D. (1982) The Crayfish Visual System: Intracellular Studies and Morphologies of Identified Neurons. Ph.D. dissertation, Rice University, Houston.

Kirk, M. D., B. Waldrop, and R. M. Glantz (1982) The crayfish sustaining fibers: I. Morphological representation of visual receptive fields in the second optic neuropil. J. Comp. Physiol. 146: 175-179.

Kirk, M. D., B. Waldrop, and R. M. Glantz (1983) The crayfish sustaining fibers: Responses to illumination, membrane properties and adaptation. J. Comp. Physiol. 150: 419-425.

Konishi, S., and E. Kravitz (1978) The physiological properties of amine-containing neurones in the lobster nervous system. J. Physiol. (Lond.) 279: 215-229.

Marder, E. E. (1974) Acetylcholine as an excitatory neuromuscular transmitter in the stomatogastric system of the lobster. Nature 251: $730-731$.

Marder, E. E. (1976) Cholinergic motor neurones in the stomatogastric system of the lobster. J. Physiol. (Lond.) 257: 63-86.

Marder, E., and J.S. Eisen (1984) Transmitter identification of pyloric neurons: Electrically coupled neurons use different transmitters. J. Neurophysiol. 51: 1345-1361.

Marder, E., and D. Paupardin-Tritsch (1978) The pharmacological properties of some crustacean neuronal acetylcholine, gamma-aminobutyric acid and L-glutamate responses. J. Physiol. (Lond.) 280: 213-236.

Marder, E., and D. Paupardin-Tritsch (1980) The pharmacological profile of the acetylcholine response of a crustaccan muscle. J. Exp. Biol. 88: 147-159.

Marder, E., S. L. Hooper, and J. S. Eisen (1987) Multiple neurotransmitters provide a mechanism for the production of multiple outputs from a single neuronal circuit. In Synaptic Function, G. M. Edelman, W. E. Gall, and W. M. Cowen, eds., pp. 305-327, Wiley, New York.

Maxwell, G. D., and J. Hildebrand (1981) Anatomical and neurochemical consequences of deafferentation in the development of the visual system of the moth, Manduca sexta. J. Comp. Neurol. 195: 667-680.

Miller, R. F., and M. M. Slaughter (1986) Excitatory amino acid receptors of the retina: Diversity of subtypes and conductance mechanisms. Trends Neurosci. 9: 211-218.

Shaw, S. R. (1984) Early visual processing in insects. J. Exp. Biol. 112: 225-25I.

Siwicki, K. K., and C. A. Bishop (1986) Mapping of protolin-like immunoreactivity in the nervous systems of lobster and crayfish. J. Comp. Neurol. 243: 435-453.

Stewart, W. W. (1978) Functional connections between cells as revealed by dye-coupling with a high fluorescent naphthalimide tracer. Cell 14: 741-759.
Strausfeld, N. J., and J. A. Campos-Ortega (1977) Vision in insects: Pathways possibly underlying neural adaptation and lateral inhibition. Science 195: 894-897.

Strausfeld, N. J., and D. R. Nassel (1980) Neuroarchitectures serving compound eyes of crustacea and insects. In Handbook of Sensory Physiology, vol. VII/6B, H. Autrum, ed., pp. 1-132, Springer-Verlag, Berlin.

Suter, C., and N. R. Usherwood (1985) Action of acetylcholine and antagonists on somata isolated from locust central neurons. Comp. Biochem. Physiol. 80c: 221-229.

Takeuchi, A., and N. Takeuchi (1966) On the permeability of the presynaptic terminal of the crayfish neuromuscular junction during synaptic inhibition and the action of gamma-aminobutyric acid. $J$. Physiol. (Lond.) 183: 433-449.

Wachtel, H., and E. R. Kandel (1971) Conversion of synaptic excitation to inhibition at a dual chemical synapse. J. Neurophysiol. 34 . $56-68$.

Waldrop, B. R. (1984) The second optic lobe of the crayfish visual system: Organization of columnar and extra columnar pathways. Ph.D. dissertation, Rice University, Houston.

Waldrop, B., and R. M. Glantz (1985a) Synaptic mechanisms of a tonic EPSP in crustacean visual interneurons: Analysis and simulation. J. Neurophysiol. 54: 636-650.

Waldrop, B., and R. M. Glantz (1985b) Nonspiking local interneurons mediate surround inhibition in crayfish sustaining fibers. J. Comp. Physiol. 156: 763-774.

Wang-Bennett, L., and R. M. Glantz (1987a) The functional organization of the crayfish lamina ganglionaris. I. Nonspiking monopolar neurons. J. Comp. Physiol. 161: 131-145.

Wang-Bennett, L., and R. M. Glantz (1987b) The functional organization of the crayfish lamina ganglionaris. II. Large field spiking and nonspiking cells. J. Comp. Physiol. 161: 147-160.

Wang-Bennett, L., C. Pfeiffer, J. Arnold, and R. M. Glantz (1989) Acetylcholine in the crayfish optic lobe: Concentration profile and cellular localization. J. Neurosci. 9: 1864-1871.

Wiersma, C. A. G., and T. Yamaguchi (1967) Integration of visual stimuli by the crayfish nervous system. J. Exp. Biol. 47: 409-431.

Yamaguchi, T., and T. Ohtsuka (1973) Dual channeling mechanism of brightness and dimness information in the crayfish visual system. J. Fac. Sci. Hokkaido Univ. Ser. VI Zool. 19: 15-30.

Yoshino, M., K. Masuda, and M. Hisada (1984) The effects of acetylcholine, carbamylcholine and GABA on uropod motoneurons in crayfish, Procambarus clarkii and Cambroides japonicus. Comp. Biochem. Physiol. 78c: 295-300. 